\title{
La Unidad Popular 30 años después
}

\author{
RODRIGO BAÑO (EDITOR) \\ Departamento Sociología Facultad De Ciencias Sociales Universidad De Chile Impresión $Y$ \\ Diagramación Lom Ediciones. 360 Páginas.
}

El hecho de que haga esta reseña quién editó el libro y escribió en él no permite que se pueda pretender aquí una visión crítica y objetiva de éste. No obstante, al menos asegura que quién hace la reseña leyó efectivamente el libro, cosa que no siempre ocurre, según dice el eterno resentido. De manera que, al menos, se espera exponer con brevedad y claridad el texto.

"La Unidad Popular 30 años después" es el resultado escrito de un Seminario del mismo nombre que se desarrolló en la Facultad de Ciencias Sociales durante toda una semana del mes de mayo de 2003 y en el cual participaron connotados intelectuales que vivieron esa experiencia y que están en condiciones treinta años después de hacer un balance de aquel proceso. Naturalmente que el hecho de que el texto sea el resultado del trabajo de varios autores es un elemento que seguramente influye en la evaluación que de él se haga, ya sea para bien o para mal.

Además de la necesaria introducción, el libro consta de cinco partes, cuatro de las cuales se refieren a la tradicional separación de aspectos de un proceso social y tienen una presentación inicial hecha por jóvenes licenciados de sociología que estudiaron previamente el tema en su Seminario de Grado, mientras que en la quinta se pretende hacer un análisis más general de éste.

En Proyecto y Proceso Económicos, la presentación del tema está a cargo de Jéssica Neicún y participan como expositores Hugo Fazio, Ricardo Ffrench-Davis y Arturo León.

En el tema Partidos y Actores Políticos, la presentación la realiza Fernando Alvear y participan aquí Angel Flisfisch, Genaro Arriagada y Jorge Arrate.

En el análisis de Movimientos Sociales, presenta el tema Liliana Manzano y Sebastián Zeiss y escriben Sergio Gómez, sobre movimiento agrario, Helia Henríquez, sobre movimiento obrero, y Gabriel Salazar sobre el sujeto popular. 
El tema Cultura es presentado por María Berríos y exponen sus trabajos Grínor Rojo, Francisco Brugnoli y Bernardo Subercaseaux.

En la final mesa redonda de análisis general participan Manuel Antonio Garretón, Oscar Godoy, Hugo Zemelman y el que aquí escribe, Rodrigo Baño.

No es fácil hacer un balance de la Unidad Popular, y está claro que este texto es sólo una aproximación a esto, como se suele decir con falsa o verdadera modestia. Sin embargo, es interesante señalar que, por premonición o por coincidencia, este Seminario, que dio lugar al texto que se presenta, se constituyó en el primero de una serie de iniciativas que en el año 2003 instauraron por primera vez un marcado interés por la experiencia de la Unidad Popular. No es exagerado decir que los recuerdos por la Unidad Popular eclipsaron los tradicionales recuerdos del golpe militar y de las características del régimen que ahí se inició. En tal sentido, los análisis que se exponen en este libro constituyen sin duda un gran aporte para quiénes ahora experimentan este renovado interés en la experiencia de la Unidad Popular. Cada uno de los temas tratados muestra distintas perspectivas de análisis y aporta información relevante para los que desean conocer y evaluar lo entonces ocurrido. Es evidente que quiénes escriben en este libro tiñen algunas veces su análisis con un fuerte componente valorativo, lo cual por cierto no tiene nada de extraño, especialmente tratándose de personas que participaron en el proceso que aquí estudian. Se trató en la organización del Seminario de obtener la participación de intelectuales de distintas posiciones políticas respecto del proceso. Esto no porque se crea que la objetividad se constituye mediante un promedio de distintas posiciones de valor, sino porque suele suceder que el compromiso afectivo con una determinada posición aclara la visión de algunos hechos y obscurece la de otros. Está claro que tiende aquí a primar la participación de quiénes estuvieron del lado de la Unidad Popular, lo que tampoco impide que sean críticos a ella, pero la renuencia a participar por parte de intelectuales más duramente contrarios a ella no pudo ser superada.

Es posible que la brevedad de algunos de los textos recogidos en este libro, o el especial abordaje que se haga en algunos casos, deje insatisfechos a muchos que quisieran un análisis de mayor extensión y profundidad. No obstante creo que es un buen comienzo para cualquiera que quiera empezar a enfrentar seriamente el tema. En todo caso, no es casual que se haya agotado rápidamente la modesta edición distribuida en librerías. 